\title{
Colocar Portugal no Mapa da Maior Experiência Química de Sempre
}

\section{A UNESCO (Organização das Nações} Unidas para o Ensino, a Ciência e a Cultura) e a IUPAC (União Internacional de Química Pura e Aplicada) aprovaram e puseram em marcha o Ano Internacional da Química (AIQ/IYC 2011), contando com o apoio entusiástico da população mundial dos químicos em geral, e das respectivas organizações nacionais aderentes (NAO). Em Portugal, a Sociedade Portuguesa de Química tem primado por imprimir brilho às celebrações do AIQ 2011, quer divulgando actividades de vários indivíduos e instituições, quer tomando a iniciativa de actividades próprias, quer ainda patrocinando actividades recomendadas pela IUPAC. Nesta última categoria insere-se a Experiência Global. Um grupo de trabalho estabelecido pela IUPAC lançou, recolheu e discutiu ideias e propostas, acabando por seleccionar e desenvolver a experiência "Água, uma Solução Química”, que compreende 4 actividades, " $\mathrm{O} \mathrm{pH}$ das Águas do Planeta, Água Límpida e Desinfectada, Águas Salgadas e Destilador Solar". As razões e os objectivos encontram-se amplamente divulgados (http://water.chemistry2011. org; http://www.spq.pt). A intenção é que uma, ou mais, destas actividades sejam realizadas pelo maior número de pessoas em todo o mundo. Por isso e para isso, os protocolos elaborados e disponíveis na Internet, em inglês e em várias traduções (uma delas em português) dirigem-se aos níveis de escolaridade do Ensino Básico e Secundário, podendo ser desenvolvidas e exploradas a níveis mais avançados consoante os interesses e as possibilidades dos experimentadores, nomeadamente no contexto de investigação científica actual. A Experiência Global está em marcha com o apoio de várias instituições nacionais e internacionais e, fazendo uso das possibilidades informáticas actuais, foi lançado um mecanismo de inscrição dos participantes, a quem se apela para que submetam, a uma base de dados central, os resultados das determinações experimentais efectuadas. Com o patrocínio da IUPAC e da European Schoolnet foram criados mapas-mundo interactivos que irão acumulando e mostrando o índice de participação nas actividades (Figura 1). Poderão igualmente ser submetidas fotografias que se candidatam a selecção para publicação on-line. Pretende-se atingir elevado nível de participação para divulgação na cerimónia de encerramento do AIQ 2011, a 1 de Dezembro de 2011, em Bruxelas e para o mundo! Louva-se a adesão de muitos grupos portugueses, embora esteja a ser reduzido o número de inscrições formalizadas, logo a respectiva visibilidade no mapa. No entanto, apesar dos múltiplos esforços de divulgação, com sessões desde os Açores até Braga, passando por Almodôvar, Lisboa, Queluz, Benavente, Caldas da Rainha, etc., verifica-se ainda, lamen- tavelmente, um intrigante desconhecimento ou alheamento desta iniciativa. As actividades visam tópicos curriculares, não implicando esforço, recursos ou tempo extra, sendo antes uma óptima oportunidade de aproveitar, de uma forma simples, um investimento feito pela comunidade científica internacional, o que só por si e além do mais, constitui uma confortável e apreciada garantia de harmonização e nivelamento.

O início, em Setembro do ano lectivo 2011/2012, é ainda uma excelente oportunidade para participar e cumprir este objectivo, que não é de menor importância. Para além dos contactos directos via internet, a Experiência Global encontra-se em pleno funcionamento, em, além de várias escolas do País, no Departamento de Química e Bioquímica da Faculdade de Ciências da Universidade de Lisboa, no Centro de Interpretação Ambiental de Vila do Conde e no Centro Ciência Viva do Lousal, onde, em caso de necessidade, poderá ser obtido apoio.

Entre os participantes portugueses será sorteada uma lembrança a divulgar oportunamente.

Maria Filomena Camões (fcamoes@fc.ul.pt)

Membro do Grupo de Trabalho da IUPAC e Coordenadora Nacional para a Experiência Global

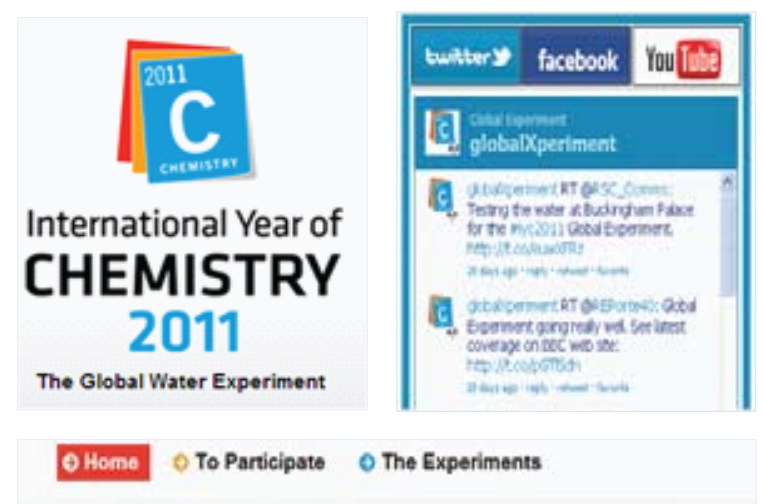

20 and 50 maits mags for the Exgerment 2

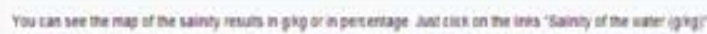

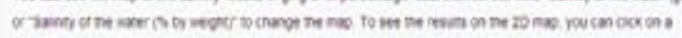

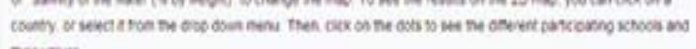
nervans

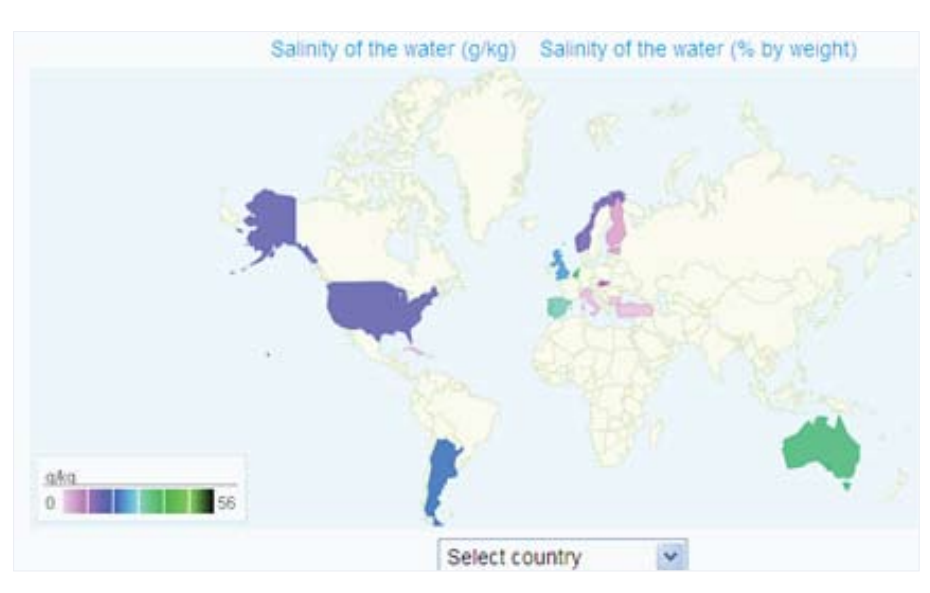

Figura 1 - Mapas-mundo interactivos onde são compilados os resultados obtidos na Experiência Global 

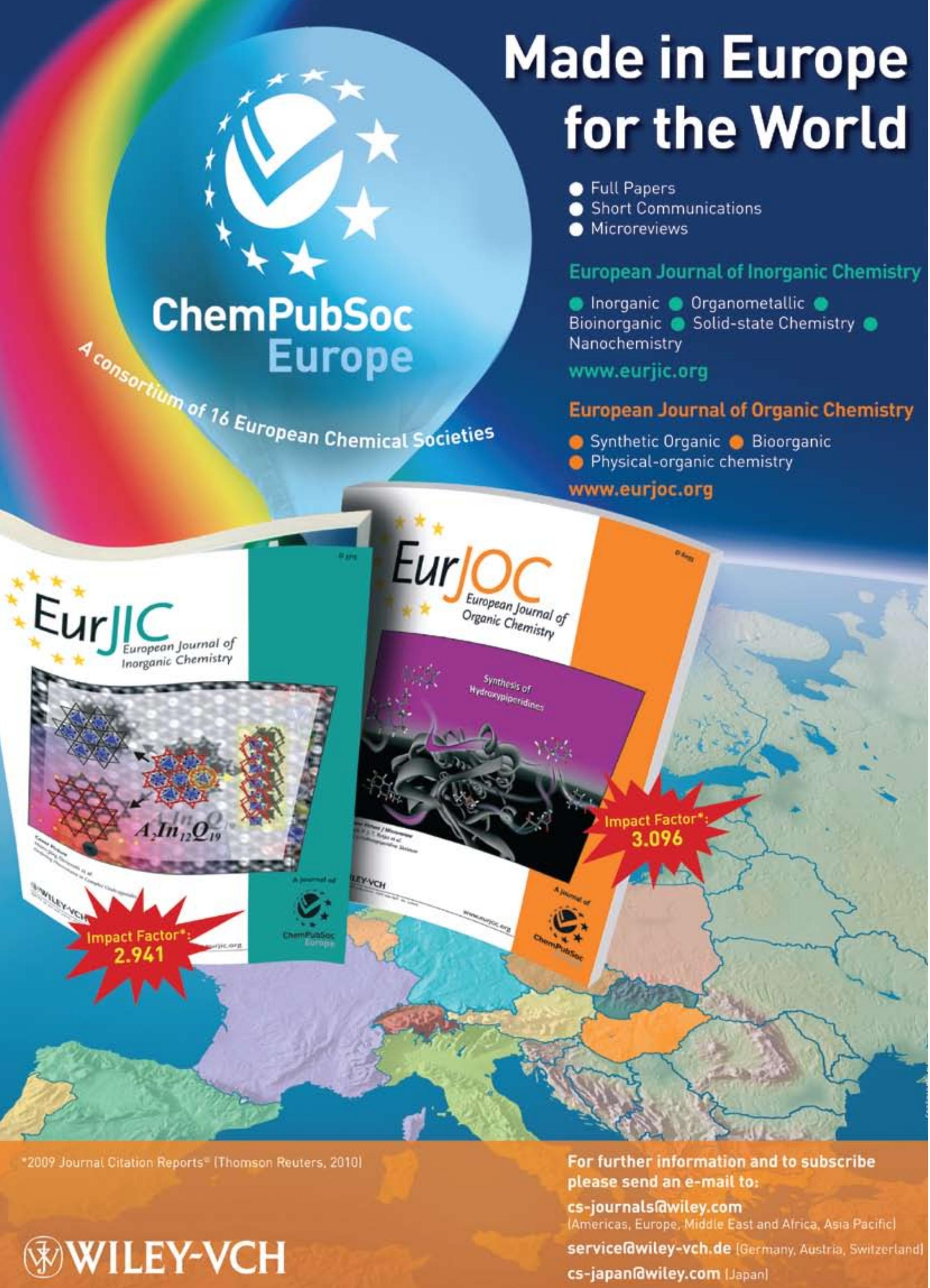